\title{
Socio-demographic characteristics of patients with diagnosed functional dyspepsia
}

\author{
Grażyna Piotrowicz', Beata Stępieñ², Grażyna Rydzewska ${ }^{2,3}$ \\ ${ }^{1}$ Gastroenterology Sub-department, MSW Hospital, Gdansk, Poland \\ 2Department of Internal Medicine and Gastroenterology, Central Clinical Hospital of Ministry of Home Affairs, Warsaw, Poland \\ ${ }^{3}$ Faculty of Health Studies, Jan Kochanowski University of Humanities and Sciences, Kielce, Poland
}

Prz Gastroenterol 2013; 8 (6): 354-365

DOI: $10.5114 / p g .2013 .39918$

Key words: epigastric pain, functional dyspepsia, Helicobacter pylori infection, seasons, endoscopy, eradication.

Address for correspondence: Grażyna Piotrowicz MD, PhD, MSW Hospital, 4/6 Kartuska St, 80-104 Gdańsk, Poland, phone: +48 602 784 507, e-mail: piotrowicz.grazyna@interia.eu

\begin{abstract}
Introduction: The term "dyspepsia" comes from the Greek words "dys' and 'peptin", which maen "ill digestion" or indigestion, although this set of symptoms in the adult clinic has little to do with the digestion or absorption process, and refers more to ailments related to the upper section of the gastrointestinal tract.

Aim: Assessment of the frequency of functional dyspepsia diagnosis, the characteristics of the group and an attempt to identify the accompanying symptoms, assessment of histological lesions and an attempt to answer question about the efficiency of anti-secretory and eradication therapy.

Material and methods: The study involved patients reporting for gastrofiberscopic examination due to dyspeptic ailments. A total of 230 patients were examined, including 140 women and 90 men, above 18 years of age. They underwent endoscopic examination, and a selected group with functional dyspepsia (FD), analysed using the 'Gast' questionnaire, underwent eradication therapy or proton pump inhibitors. Statistical analysis involved $\chi^{2}$ and Fischer's test.

Results: The study involved 230 individuals with dyspeptic disorders. The largest age group was $46-60$ years. These patients reported due to their ailments mostly in autumn and winter. The differentiated group with FD included 53 patients (23\% of the clinical population). $69.8 \%$ of the FD group was infected with Helicobacter pylori (with $81.2 \%$ of the whole population, respectively). Individuals with FD reported improvement more often after being administered drugs to decrease gastric secretion, more often declared post-elementary education and suffered from non-gastric ailments yet still described their state of health as good. No positive therapeutic effect of eradication was noticed during the 6-month observation.

Conclusions: Due to the very high ratio of subjects with functional dyspepsia, also observed in the study sample, and the influence of civilization progress, we should expect increasing frequency of occurrence of this problem.
\end{abstract}

\section{Introduction}

The term 'dyspepsia' comes from the Greek words 'dys' and 'peptin', which mean 'ill digestion' or indigestion, although this set of symptoms in the adult clinic has little to do with the digestion or absorption process, and refers more to ailments related to the upper section of the gastrointestinal tract, such as midepigastric pain or discomfort [1]. This can be due to various illnesses with accompanying mucous membrane damage, and then it is called organic dyspepsia. If we do not know the organic background of the illness, we talk about so-called functional dyspepsia [2]. It is assumed that it occurs on average in $25 \%$ of the adult western society population [3]. The exact frequency is hard to determine because, as in the case of most functional diseases, a large group of patients fail to seek medical help.

Functional dyspepsia is a serious diagnostic-therapeutic problem for gastro peptic system (GPs), internists and gastroenterologists. A few potential pathogenetic factors are differentiated in the aetiopathogenesis of functional dyspepsia [1, 4-6]:

1) experiencing harmful stimuli (nociceptive);

2) motor dysfunction;

3) central nervous system dysfunction (e.g. increased sensitivity to serotonin);

4) psychogenic factors (e.g. enhanced reactions to stress, aggression, conflicts); 
5) environmental factors (e.g. Helicobacter pylori infection, smoking cigarettes).

The currently binding definition of functional dyspepsia is based on the so-called Rome Diagnostic Criteria III, according to which dyspepsia refers to epigastric pain or discomfort, i.e. the patient feels it mostly in their mid-body line or close to it. Discomfort is a subjective, unpleasant feeling not experienced as pain by a patient. Discomfort may have the form of the sense of epigastric fullness or an early feeling of satiety, flatulence or nausea; these symptoms are accompanied by the feeling of epigastric 'discomfort' [7-9].

It is commonly agreed that in order to diagnose functional dyspepsia it is necessary to diagnose chronic ailments, in accordance with the currently binding definition [6]. Revealing the nature of ailments is insufficient to differentiate correctly between organic and functional dyspepsia. The latter is diagnosed after making sure that a patient does not suffer from any other disease; it is also recommended that gastroscopy and an ultrasound examination of the abdominal cavity be conducted. In the event of so-called alarm symptoms, i.e. losing weight, fever and/or hematemesis, it is necessary to conduct more detailed diagnostics, including biochemical tests [7, 9-11].

It is uneconomical to conduct endoscopic examinations in all patients with dyspepsia. Empirical therapy using proton pump inhibitors is cheaper than an invasive examination. Empirical administration of drugs decreasing gastric secretion may lead to mistaken diagnosis of functional dyspepsia in the group with peptic ulceration but who responded to the aforementioned treatment. It was revealed that $2 / 3$ of patients who were administered drugs decreasing gastric secretion underwent the endoscopic examination anyway some time later [12-15].

The rules of therapeutic command should be based on pathophysiology, the directives of which are unclear in cases of functional dyspepsia. Many studies have been conducted which have analysed the influence of drugs decreasing gastric secretion, prokinetic drugs, alkalizing drugs and finally - eradication therapy and administration of antidepressants [7, 16, 17].

Approximately $25-50 \%$ of patients with functional dyspepsia also have symptoms related to hypomotor functioning of the stomach, and about $10 \%$ - dysrhythmia. No significant correlation was determined between motor disorders and the symptoms, yet prokinetic drugs are quite commonly used in dyspepsia of the motor type [18]. Many patients demonstrate symptoms which indicate increased gastric secretion, which qualifies them to dyspepsia of the ulcer type. Additionally, some of them have histological features of gastric mucus membrane inflammation, which suggests that administering drugs decreasing gastric secretion should improve the patients' mood [7, 19, 20].

In functional dyspepsia treatment the intensity, duration and impact of symptoms on quality of life should be taken into account [21-23]. The optimum therapy time is unknown. The general practice is to administer drugs until symptoms cease. If ailments continue for 2-4 weeks, increasing drug dosage or introducing combined treatment should be considered. Many patients have recurring ailments, a fact which enforces the readministration of treatment [15, 22, 24]. In the group of dyspeptic patients, as in the case of many other functional diseases, a high response to placebo is observed; according to the literature, this figure is as high as $60 \%$. Approximately $50 \%$ patients with functional dyspepsia are infected with $\mathrm{H}$. pylori [3]. No significant result in mood assessment was observed after applying eradication, which puts the sense of such therapy into question, although there is no sufficient evidence yet to confirm this thesis $[25,26]$. Empirical treatment of functional dyspepsia will prevail as long as there is no clear and certain pathophysiological image of this disease [26-28].

\section{Aim}

A review of literature about functional dyspepsia reveals a lot of doubts and ambiguities concerning this group of patients, both in terms of diagnosing the illness and its treatment. The role of $\mathrm{H}$. pylori and the relation between dyspeptic symptoms and gastric mucus membrane inflammation remains unknown. There is also no current data concerning the occurrence of functional dyspepsia in the Polish population or the profile of patients reporting such symptoms.

Due to this, the following aims were formulated for this thesis: 1) an assessment of the frequency of diagnosis of this illness in a group of patients reporting dyspeptic symptoms in an endoscopic laboratory; 2) an attempt to identify accompanying symptoms occurring with patients with functional dyspepsia, characteristic of this group; 3 ) an assessment of histopathological lesions in this group of patients and an assessment of $H$. pylori infection; 4) an attempt to answer questions concerning the efficiency of anti-secretion and eradication therapy in patients with functional dyspepsia.

\section{Material and methods}

The study involved patients recruited from individuals referred to gastrofiberscopic examination due to reported dyspeptic ailments, to the Endoscopic Laboratory in the MSWiA Hospital in Olsztyn, following consent issued by the Bioethics Committee established under the 


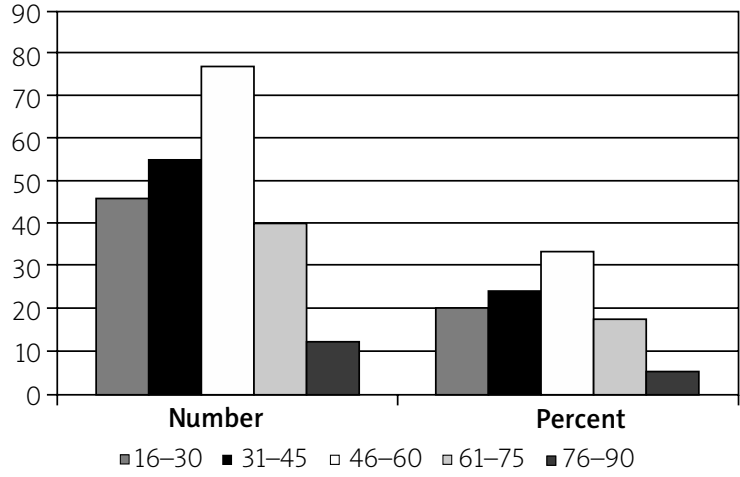

Figure 1. Division of the clinical population into age categories (years)

auspices of the Regional Medical Chamber in Olsztyn, Poland.

All patients reporting dyspeptic symptoms were initially assessed using the Rome Diagnostic Criteria II for diagnosing dyspepsia. Patients who were qualified for further observation did not have any so-called alarm symptoms, i.e. fever, loss of body weight or blood in faeces. Also, all patients whose symptoms could - according to the Rome Criteria II - match irritable bowel syndrome, i.e. defecation disorders, were excluded from further study, along with patients with dominant symptoms of reflux disease.

Eventually the study sample consisted of $230 \mathrm{pa}-$ tients, 90 men and 140 women, aged above 18 years.

All patients filled in a detailed Gast questionnaire and then underwent gastrofiberscopic examination, with typical macroscopic assessment of gastric mucus membrane. From the group of patients examined endoscopically, those without macroscopic endoscopic lesions were selected and qualified in accordance with the binding definition to the functional dyspepsia group. All patients with diagnosed functional dyspepsia were administered lansoprazole $30 \mathrm{mg}$ in two doses for 7 days. The eradicated group was also administered clarithromycin $500 \mathrm{mg}$ dosed twice a day, and amoxicillin 1000 mg dosed twice a day for 7 days. Then both groups continued to be treated with lansoprazole dosed $1 \times 30 \mathrm{mg}$ for 4 weeks.

Table I. Frequency of dyspeptic ailments depending on seasons

\begin{tabular}{lcc} 
Season & Number & Percent \\
\hline Winter & 70 & 30.4 \\
\hline Spring & 33 & 14.4 \\
\hline Summer & 55 & 23.9 \\
\hline Autumn & 72 & 31.3 \\
\hline Total & $\mathbf{2 3 0}$ & $\mathbf{1 0 0}$
\end{tabular}

\section{Statistical analysis}

Statistical analysis was conducted using $\chi^{2}$ and Fischer's test. The null hypothesis assumed the independence of variables, the alternative hypothesis assumed their dependence. In most cases Pearson's $\chi^{2}$ independence test was used, with a significance level of $p=0.05$. The number ' $p$ ', which is used further on in the thesis, stands for the computer-labelled probability level, also known as the test probability. Results for which $p$ is smaller than 0.05 (default significance level) are statistically significant, i.e. there is a correlation between the features. The $\chi^{2}$ test was modified in order to create a more appropriate test. The used computer program accepted the option of corrections. Yates's correction was applied because in a few cases of small $2 \times 2$ tables the expected headcount was smaller than 5 .

\section{Results}

Sociodemographic characteristics

of the whole study sample $(n=230)$

As previously mentioned, 230 individuals with dyspeptic symptoms were qualified to the study. None of them had ever undergone endoscopic diagnostics. The group included 140 women (60.9\%) and 90 men (39.1\%).

The age characteristics of the group are presented in Figure 1. The largest - as it turns out - age group of patients with dyspepsia is the 46- to 60-year-old, group and the second largest group includes mature people in the 'productive' age from 31 to 45 years. It is worth noting that dyspepsia also affects very young patients.

The data contained in Table I and shown in Figure 2 refer to the frequency of dyspeptic symptoms in subjects at different times of the year. It should be added that the study of these patients was made so as to cover all the seasons. The presented figures and charts clearly show that dyspepsia often appears in autumn and winter, and less frequently in spring and summer. The difference between the number of people presenting with dyspeptic complaints during autumn-winter and spring-summer turned out to be statistically significant $(p>0.05)$.

It seems that a satisfactory explanation of this relation is very difficult - if not impossible. We can only assume that change of climate is implicated in the experience of pain. Perhaps the appearance of symptoms is facilitated by adverse changes in mood and wellbeing during autumn and winter, which is often reported by patients. Or maybe it is just that in autumn and winter people have more time to take care of their health and report experienced exacerbation of dyspeptic symptoms.

The next Table II and Figure 3 show the results of endoscopic examinations, which embraced all peo- 


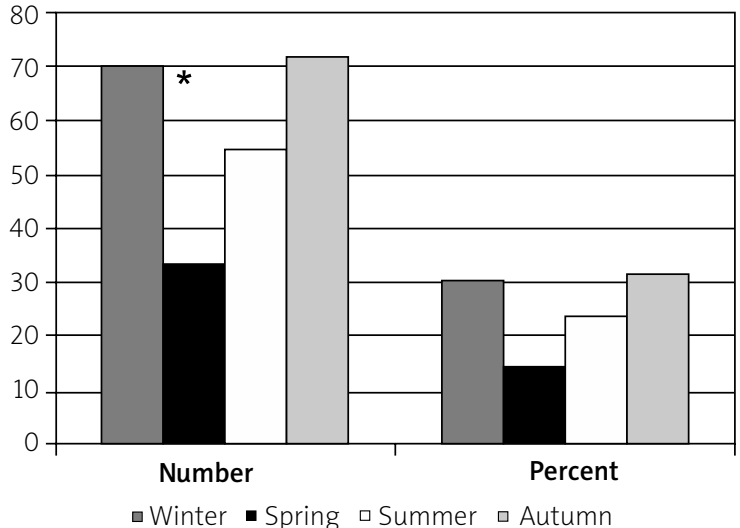

Figure 2. Dyspeptic ailments depending on seasons $\left({ }^{*} p<0.05\right)$

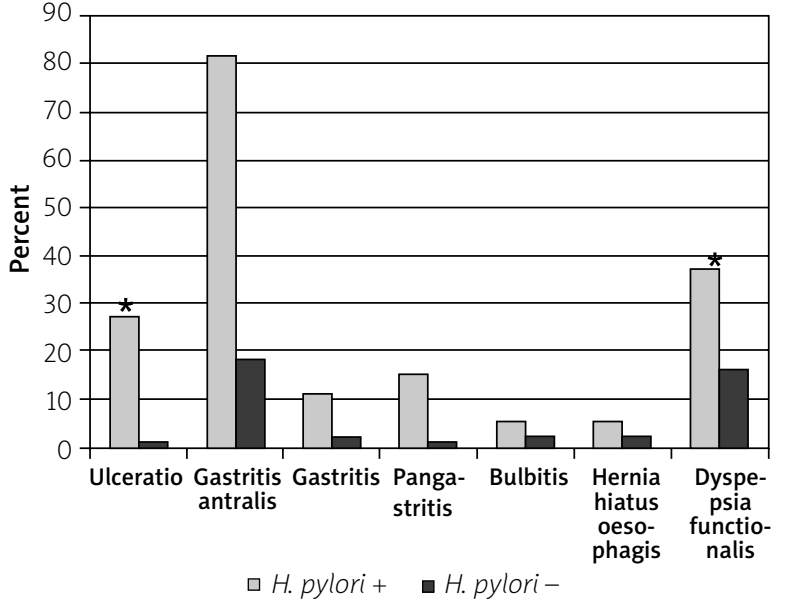

Figure 3. Helicobacter pylori infection in subsequent illness groups $\left({ }^{*} p<0.05\right)$

women and men with differentiation of subsequent illnesses indicates significant statistical variety.

In the cases of gastritis antralis, bulbitis and dyspepsia functionalis, we note a significantly higher number of women. This was true especially for functional dyspepsia, where symptoms are reported much more frequently by women than by men. Ulceration and cancer were also observed as significantly more frequent among men.

Table II. Division of the clinical population into illness groups depending on endoscopic image

\begin{tabular}{lcc} 
Illness group & Number & Percent \\
\hline Gastritis antralis & 100 & 43.5 \\
\hline Gastritis & 13 & 5.7 \\
\hline Pangastritis & 16 & 7.0 \\
\hline Ulcus & 28 & 12.2 \\
\hline Hernia hiatus oesophagi & 7 & 3.0 \\
\hline Bulbitis & 7 & 3.0 \\
\hline Ca ventriculi & 6 & 2.6 \\
\hline Dyspepsia functionalis & 53 & 23.0 \\
\hline Total & $\mathbf{2 3 0}$ & 100
\end{tabular}

Table III. Assessment of Helicobacter pylori infection in the clinical population using urease test

\begin{tabular}{lcc} 
Infection result & Number & Percent \\
\hline Positive & 182 & 81.2 \\
\hline Negative & 42 & 18.8 \\
\hline Total & $\mathbf{2 2 4}$ & $\mathbf{1 0 0}$
\end{tabular}




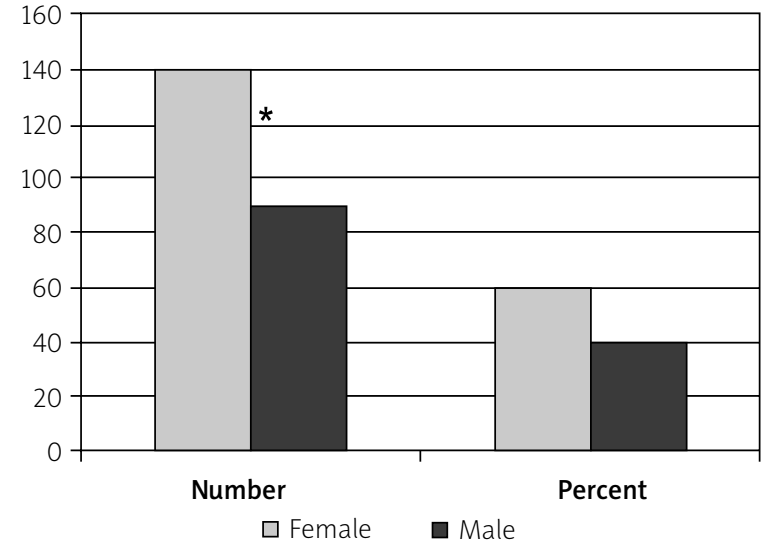

Figure 4. Sex in the clinical population with dyspeptic ailments $\left({ }^{*} p<0.05\right)$

Figure 4 shows that dyspeptic ailments occur much more frequently among women than among men. The variation level is statistically significant.

The Table $V$ and Figure 6 refer to variables indicating a connection between the respondents and the kinds of illnesses they manifest. Five age subgroups were differentiated among all subjects. The distribution of results shows that the least frequent illnesses, gastritis (13 cases) and pangastritis (16 cases), were 'spread' more or less equally among all age groups.

The most frequent illness was gastritis antralis (100 persons from among 230 subjects), which occurred most frequently in the $2^{\text {nd }}$ and $3^{\text {rd }}$ age subgroups, i.e. between 31 and 60 years of age. Dyspepsia functionalis is the second most frequently occurring disease in the study sample (53 subjects). It most often appears in the age groups $16-30$ years and $31-45$ years, i.e. among young people. It is also worth noting that subjects from groups 3 (46-60 years) and 2 (31-45 years) had the largest number of illnesses.
Referring to the earlier analysis of the relation between dyspeptic symptoms and seasons, the potential relation between seasons and macroscopic changes was analysed as well (Table VI, Figure 4). No seasonality described in literature was observed, according to which ailments occur more often in spring and autumn; in the study sample inflammatory lesions such as gastritis antralis occurred statistically more often in winter, functional dyspepsia - in autumn, and in spring very few patients reported with dyspeptic symptoms. In the case of other disorders, no statistically significant differences were observed among the number of patients seeking medical help in different seasons.

\section{Functional dyspepsia group characteristics $(n=53)$}

In accordance with the assumptions, the aim of this thesis was first of all to analyse the functional dyspepsia group, which comprised $23 \%$ of the clinical population. This group was considered in terms of gender, stating the statistically significant predominance of women (42 persons, representing 79.2\%) (Figure 5), and in terms of age; the illness was most commonly found in age groups 1 and 2 (Figure 6). Given that in the whole study sample the greatest purity of symptoms occurred in group 3, i.e. in patients between 45 and 60 years of age, it seems clear that in group 3 dyspeptic symptoms were generally accompanied by macroscopic limited lesions in the gastric mucosa.

The presented characteristic of patients diagnosed with functional dyspepsia contains some of the data included in the previously aggregated tables and figures, but for convenience they are repeated. To sum up the characteristics of the study sample, it should be noted that functional dyspepsia in the material was significantly more frequent among women $(p<0.05)$ and

Table IV. Dependence between illness groups and sex

\begin{tabular}{|c|c|c|c|c|c|}
\hline Illness & $F$ & $M$ & Total & $\chi^{2}$ & Value of $p$ \\
\hline Ulceratio & 12 & 16 & 28 & 5.93 & $<0.05^{\star}$ \\
\hline Gastritis antralis & 60 & 40 & 100 & 0.085 & $>0.05$ \\
\hline Gastritis & 8 & 5 & 13 & 0.055 Yates & $>0.05$ \\
\hline Pangastritis & 8 & 8 & 16 & 0.84 & $>0.05$ \\
\hline Bulbitis & 6 & 1 & 7 & 1.88 & $>0.05$ \\
\hline Hernia hiatus oesophagi & 3 & 4 & 7 & 0.98 Yates & $>0.05$ \\
\hline Ca ventriculi & 1 & 5 & 6 & 4.5 Yates & $<0.05^{\star}$ \\
\hline Dyspepsia functionalis & 42 & 11 & 53 & 9.87 & $<0.05^{*}$ \\
\hline Total & 140 & 90 & 230 & 24.877 & $\begin{array}{l}<0.05^{*} \\
(0.002)\end{array}$ \\
\hline
\end{tabular}

F-female, $M$ - male 
among the younger patients (age groups 1 and 2). It should be noted that more than $75 \%$ of patients diagnosed with functional dyspepsia belonged to 45 years age group. It is a common feature for other functional disorders, such as irritable bowel syndrome.

There were no signs of typical seasonality in patients with functional dyspepsia, although these patients significantly more often reported in the autumn, and the least often in the spring (Table VII).

Another feature of the analysed group of patients with functional dyspepsia was $H$. pylori infection. It was found that the $H$. pylori infection rate in this group was $69.8 \%$, it was statistically significantly higher than in the other groups, although less than in the overall population (81.2\%) (Tables III and VIII, Figure 3), which may be affected by the group of patients with peptic ulcer disease, in which the frequency of both the group and the role of pathogenic infection is indisputable.

Helicobacter pylori infection in the group with functional dyspepsia was evaluated both by means of a urease test and histological examination. Strong statistical correlation was obtained ( $p<0.0001)$, which again indicates the parallelism of these two tests.

During endoscopic examinations, in accordance with the recommendations of the Sydney system, samples from the stomach antrum and corpus were collected for histopathological evaluation. The degree of inflammation was assessed, and no atrophy or metaplasia lesions were revealed during microscopic evaluation in the study sample.

The following table shows that people with symptoms of functional dyspepsia, without $H$. pylori infection, in $9.4 \%$ ( 5 of 16 subjects) of cases showed no inflammatory changes in the mucosa of antrum and corpus, or the changes were minor in severity, defined as 'gastritis gr. Minoris' 20.8\% (11 of 16, and 2 of them had the type of inflammatory infiltrate that occurs in the antrum only).

In the case of the H. pylori-infected group, all subjects had microscopic changes of the mucosa, despite normal endoscopic image. A hundred percent of those

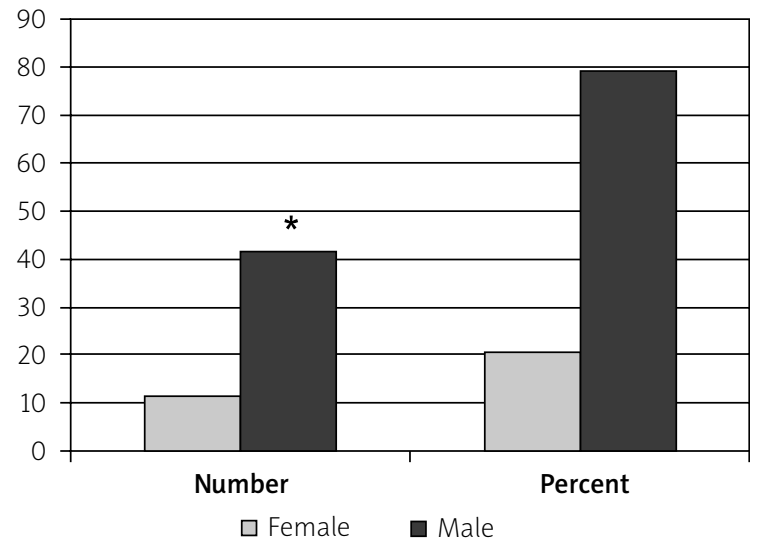

Figure 5. Sex in the group of patients with functional dyspepsia $\left({ }^{*} p<0.05\right)$

infected and showing dyspeptic symptoms also had histological lesions.

The last notable problem - in the author's opinion - is the effect of treatment on symptoms of functional dyspepsia.

The whole group with a diagnosis of functional dyspepsia - as results from the presented table - was divided into subgroups: those with $H$. pylori infection and those without $H$. pylori infection group and not eradicated/eradicated.

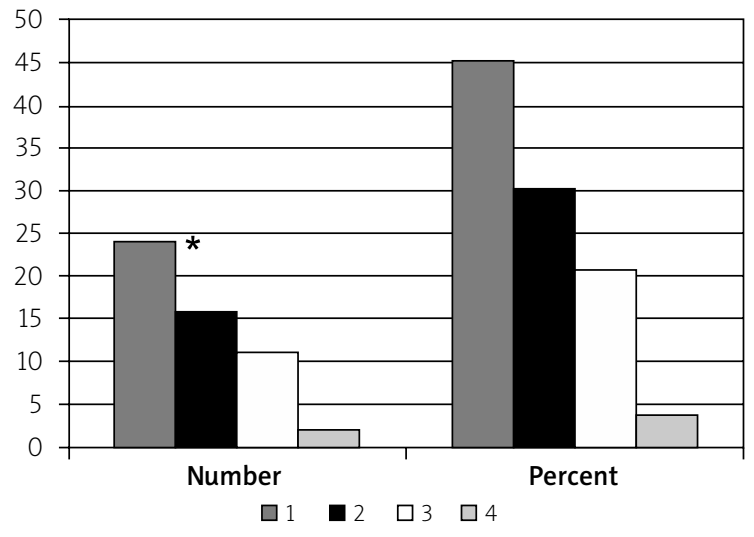

Figure 6. Age groups in functional dyspepsia $\left({ }^{*} p<0.05\right)$

Table V. Dependence between age groups in subsequent illness groups

\begin{tabular}{lcccccccc} 
Illness & $\mathbf{1}$ & $\mathbf{2}$ & $\mathbf{3}$ & $\mathbf{4}$ & $\mathbf{5}$ & Total & $\chi^{2}$ & Value of $\boldsymbol{p}$ \\
\hline Ulceratio & 2 & 9 & 8 & 6 & 3 & 28 & 6.08 & $>0.05$ \\
\hline Gastritis antralis & 14 & 26 & 38 & 18 & 4 & 100 & 5.3 & $>0.05$ \\
\hline Gastritis & 3 & 1 & 2 & 5 & 2 & 13 & 9.063 & $<0.05$ \\
\hline Pangastritis & 3 & 1 & 7 & 4 & 1 & 16 & 3.62 & $>0.05$ \\
\hline Dyspepsia functionalis & 24 & 16 & 11 & 2 & 0 & 53 & 37.5 & $<0.05$ \\
\hline Total & $\mathbf{4 6}$ & $\mathbf{5 3}$ & $\mathbf{6 6}$ & $\mathbf{3 5}$ & $\mathbf{1 0}$ & $\mathbf{2 1 0}$ & $\mathbf{6 7 . 9 8 3}$ & $<0.05$ \\
& & & & & & & $(\mathbf{0 . 0 0 0 2 )})$
\end{tabular}


Table VI. Influence of seasons on the number of patients reporting subsequent illness groups

\begin{tabular}{lccccccc} 
Illness & Winter & Summer & Autumn & Spring & Total & $\chi^{2}$ & Value of $p$ \\
\hline Ulceratio & 7 & 6 & 12 & 3 & 28 & 2.7996 & $>0.05$ \\
\hline $\begin{array}{l}\text { Gastritis } \\
\text { antralis }\end{array}$ & 38 & 22 & 22 & 18 & 100 & 10.9 & $<0.05$ \\
\hline Gastritis & 4 & 2 & 1 & 6 & 13 & 11.87 & $<0.05$ \\
& 6 & 4 & 4 & 2 & 16 & 1.2 & $>0.01)$ \\
\hline Pangastritis & 6 & 14 & 24 & 3 & 53 & 9.82 & $<0.05$ \\
\hline $\begin{array}{l}\text { Dyspepsia } \\
\text { functionalis }\end{array}$ & 12 & $\mathbf{4 8}$ & $\mathbf{6 3}$ & $\mathbf{3 2}$ & $\mathbf{2 1 0}$ & $\mathbf{4 7 . 1 4 7}$ & $<0.05(\mathbf{0 . 0 0 3 )}$
\end{tabular}

Table VII. Influence of seasons on functional dyspepsia ailments

\begin{tabular}{lcc} 
Season & Number & Percent \\
\hline Winter & 12 & 22.6 \\
\hline Summer & 14 & 26.4 \\
\hline Autumn & 24 & 45.3 \\
\hline Spring & 3 & 5.7 \\
\hline Total & $\mathbf{5 3}$ & $\mathbf{1 0 0}$
\end{tabular}

Table VIII. Helicobacter pylori infection in functional dyspepsia

\begin{tabular}{lcc} 
Urease test & Number & Percent \\
\hline Positive & 37 & 69.8 \\
\hline Negative & 16 & 30.2 \\
\hline Total & $\mathbf{5 3}$ & $\mathbf{1 0 0}$
\end{tabular}

Then all patients with functional dyspepsia were administered a 7-day course of treatment with lansoprazole $30 \mathrm{mg}$ two times a day, and a select eradicated group was administered a 7-day eradication, clarithromycin 500 mg twice per day and amoxicillin 1000 mg twice per day. Subsequently, all patients continued to receive 1 daily dose of lansoprazole $30 \mathrm{mg}$ for 4 weeks. The impact of treatment on the wellbeing of patients was evaluated after 6 weeks and 6 months. The statistical analysis revealed no beneficial influence of treatment on the wellbeing of the patients $(p>0.05)$.

\section{Characteristics of patients with functional dyspepsia on the basis of the Gast questionnaire}

Patients were qualified for the study on the basis of the Gast questionnaire, which was developed on the basis of Talley's questionnaire and was meant to assess dyspeptic ailments.

Based on the data obtained, it was found that in the case of the majority of patients reported symptoms oc- curred more frequently than 6 times a year. They were usually located in the upper abdomen (84.31\%). This pain was unlikely to awaken the patients (in 54.9\%), although a significant percentage of respondents complained about problems with night rest (45.1\%). The pain most commonly occurred periodically, i.e. it appeared and disappeared (70.59\%). In fact, the pain was not related to the time of the meal; the majority of subjects stated that it did not occur within half to $2 \mathrm{~h}$ after a meal and did not have the character of hunger pains. $90.2 \%$ of the respondents said that the pain was not resolved and did not weaken with deep breathing or after defecation, and that it was not reduced after the meal (74.51\%).

The pain resolved or alleviated after administration of drugs that reduce gastric secretion (44\%); in this case, a significant difference was also observed depending on the $H$. pylori infection, i.e. symptoms were reduced much more significantly after proton-pump inhibitor (PPI) treatment in cases of infected patients. A large group of subjects, however, did not take PPI (40\%), and these were mainly people with functional dyspepsia without $H$. pylori infection.

The abdominal discomfort was not intensified by the consumption of milk and milk products. When asked whether the pain was intensified by alcohol, more than half of the subjects reported that they did not drink alcohol (more often in the group without $H$. pylori infection). In the case of the group with $H$. pylori infection and the subjects who drank alcohol more often, no intensification of pain in the upper abdomen was observed during or depending on alcohol consumption.

Based on the questionnaire, individuals with suspected irritable bowel syndrome (IBS), bleeding from the upper and lower gastrointestinal tract, and gastroesophageal reflux disease were excluded from further study.

Similarly in both groups with functional dyspepsia (H. pylori infected and uninfected), patients complained of abdominal distension (66.7\%), there was no weight 
loss in the past year (70.59\%), and the appetite compared with previous years was evaluated as the same (58.82\%, comparable in both groups).

The subjects had no abdominal discomfort as a child - the border of 15 years of age was used in this case $(74.51 \%)$, and they had not had an appendectomy performed $(74.51 \%)$. During the initial pre-selection a group with a history of cholecystectomy was excluded from further study.

In the case of the majority (88.2\%) of patients, abdominal pain was the leading cause of doctor visits, and the pain was rated as strong or very strong (77.78\%), raising concern $(91.11 \%)$ and raising suspicion of a serious illness (51.11\%).

Daily activity in the preceeding year of life was not disturbed because of abdominal pain in more than half of the subjects $(56.86 \%)$, similarly in both treatment groups, and such a pain was not a cause of absence from work (60\%).

More than half of the respondents reported that they never smoked cigarettes (54.9\%) and at the time of the study did not smoke even one cigarette a day (64.1\%). However, the number of cigarettes smoked by respondents was higher by 5 cigarettes in the group infected with $H$. pylori than in the uninfected group, members of which barely smoked at all.

The majority of subjects did not use analgesics (76.47\%), were not treated for hypertension or coronary artery disease, had not had a cold recently (96.08\%), and thus did not take IEC drugs, Ca-blockers, nitrates or antibiotics.

The subjects predominantly remained in legal partnerships (62\%) and worked professionally (69.39\%). Regarding the education of respondents, the largest group consisted of those with secondary and higher education (altogether 54.9\%).

Half of the respondents described their health as good (52.94\%), saying that it was not (80\%) an obstacle to go to work, to take care of the household or attend school, or to do basic daily duties (78.43\%).

The subjects did not claim that they fell ill easier than other people, but when assessing the following sentence: "My health is comparable to the health of other people I know," they answered, that the sentence is "mostly false" (64.74\%).

Although this result was not presented in the Table due to a high number of answers and many options of comparing them, it should be noted that similarly in both functional dyspepsia groups, subjects complained about a feeling of nervousness, palpitations, headache, back pain, insomnia and depressed mood.

In the statistical analysis of the questionnaire, two functional dyspepsia groups were compared: a group with dyspepsia and accompanying $H$. pylori infection, and a group without this infection. It was found that among the infected subjects: 1) they significantly more often reported improved mood after the administration of drugs which decreased gastric secretion $(p<0.05)$, 2 ) dyspeptic symptoms occurred more often with persons infected with $\mathrm{H}$. pylori and among those smoking cigarettes, with significant dependence between the ailment and the number of smoked cigarettes $(p<0.05)$, 3 ) those with functional dyspepsia more often reported post-primary education, mostly secondary and higher $(p<0.05), 4)$ in spite of dyspeptic ailments, the group infected with $H$. pylori described their state of health as good significantly more often $(p<0.05)$.

\section{Discussion}

The clinical population was selected from among patients admitted to the Hospital Laboratory Endoscopic Ministry in Olsztyn. Therefore it is difficult to talk about the population incidence of dyspepsia, since all of the patients at the time of the study reported dyspeptic symptoms. All patients met the Rome Criteria II, which helped to qualify the reported symptoms as dyspeptic. Therefore, after an initial selection, a homogeneous group of 230 people was selected, all of them with dyspeptic ailments dependent on the upper gastrointestinal tract, i.e. the oesophagus, stomach and duodenum.

The results presented in the paper can be grouped into three main modules. The first part represents the characteristics of a select group of 230 people with ailments meeting Rome II criteria for dyspepsia in terms of gender, age, seasonality, endoscopic changes and H. pylori infection.

The second part is a presentation of the characteristics of the selected group with functional dyspepsia. These are similar characteristics, i.e. age, sex, the effect of the seasons on the number of patients seeking medical help, and thus the incidence or exacerbation of symptoms, $H$. pylori infection and histopathological analysis taken from macroscopically normal mucosa biopsies.

The third part is a discussion of the results of a detailed survey conducted exclusively among patients with functional dyspepsia, containing questions on the characteristics of the study group, socio-economic conditions, treatment and some components of the quality of life. The analysis of responses allowed for a detailed description of the study sample.

Summing up these considerations, we can say that the analysis shows that patients with dyspeptic complaints reported for the first time for an endoscopy usually between 46 and 60 years of age. 
Meanwhile the functional dyspepsia was diagnosed most often in the youngest group, i.e. between 18 and 45 years of age; therefore, the rate of organic changes increases with age, which seems to be justified by the statistics, driving patients after 40 years of age to undergo an endoscopic examination, or - as can be concluded from the current data - after 45 years of age. The frequency of functional dyspepsia diagnosis decreased with age, giving way to organic pathology. These differences were statistically significant. This is confirmed by the literature reports indicating a higher rate of organic pathology at the age of 45 years, suggesting that for these patients we should always conduct an endoscopic examination in case of dyspeptic symptoms. Also, the seasons in which the patients reported to the Endoscopic Laboratory were analysed: mostly it was during autumn (statistical significance). With regard to $H$. pylori infection, for the urease test of the biopsy taken during the endoscopic examination of the pyloric antrum, a positive test result was obtained in 181 patients (81.2\%).

The functional dyspepsia group consisted of 53 people, or $23 \%$ of the population. This rate was comparable with data from an Italian study (32\%) and a British study (20\%), although in a Swedish study this incidence was much higher, by as much as $63 \%$; on average it is assumed that it applies to $25 \%$ of the western population $[3,15,29,30]$. Symptoms of functional dyspepsia were observed mostly in young and middle-aged patients (16 to 45 years of age), which was confirmed in other studies. Dyspepsia, confirmed in accordance with the generally accepted criteria, was observed mainly in young women (42 persons, representing $79.2 \%$ ). They frequently reported to the laboratory because of the severity of symptoms in the autumn (24 person - 22.6\%).

In the urease test $H$. pylori infection was found in 37 patients (69.8\%). In comparative studies, infection in the group with functional dyspepsia was reported in $50 \%$ of patients $[16,23,31]$.

Due to the large percentage of uninfected subjects in the functional dyspepsia group and the large proportion of infections in patients without dyspeptic symptoms, many authors call into question the fact that $H$. pylori infection is a causative factor of this type of complaint $[32,33]$. It is suggested that the presence of H. pylori in patients with functional dyspepsia is a result of age and the average infection in the population [32, 33]. The role of this infection is not fully understood; in my research both infected and uninfected patients manifested similar ailments and similar rates of symptoms [21].

One of the most important facts emerging from the author's own research is that subjects who did not have
H. pylori infection did not show or showed only minimal inflammation of the gastric mucous membrane. However, in all (100\%) patients with $H$. pylori infection has been revealed the inflammation of the mucous of varying degrees, mainly in the antrum and predominantly of at least moderate severity. Meanwhile, a clear relation between $H$. pylori infection and the histological features of mucosal inflammation was demonstrated, both in the material analysed as well as in the cited studies. However, no differences in the symptoms of dyspepsia among infected and uninfected subjects were revealed [21, 26, 34, 35].

Do dyspeptic ailments depend on the severity of the inflammation? That question has not yet been answered in the literature.

It is worth mentioning that in the group of patients without macroscopic lesions, classified on the basis of Rome Criteria II to the functional dyspepsia group, only 5 patients (9.4\%) did not have microscopic inflammation, and these were the uninfected patients. Both the aforementioned studies and the analysis of data in this thesis indicate that mucus membrane inflammation is mainly due to $H$. pylori $[36,37]$.

Analysis of the author's own data revealed no relationship between the assessment of wellbeing in the group after eradication therapy and in the group without eradication, and the evaluation within 6 months after the end of the treatment. At the same time, the majority of patients reported improvement in wellbeing during the PPI treatment.

Another important element of the study was an attempt to characterize the sample. All patients with symptoms of dyspepsia were asked to fill out a Gast questionnaire. They reported discomfort in the upper abdomen for at least one year; the pain was of an average severity, was located above the navel, did not wake subjects from their sleep, occurred periodically and is reported to have appeared and disappeared. In most cases the ailments weakened after the administration of drugs reducing the secretion. Abdominal disorders were often accompanied by bloating. The frequency of visits to the doctor because of these symptoms was 3-5 during the year, the pain was defined as strong or very strong and the thought of cancer affliction plagued half of the respondents. The pain did not hinder their daily life activities. The majority (60\%) of respondents did not take sick leave because of the abdominal pain. A relation between the number of cigarettes smoked and dyspeptic complaints was found in the group with H. pylori infection.

Furthermore, the impact of non-steroidal anti-inflammatory drugs (NSAID) drugs and cardiac drugs (IEC, Ca-blockers, nitrates) was investigated but showed no 
statistical dependence of the characteristic. $69.4 \%$ of the subjects were professionally active, with higher or secondary education. Their health was mostly evaluated as good; they also claimed that their state of health did not significantly influence their life activities or career.

The most frequently mentioned co-existing disorders were headaches, back pain, nausea, depression, palpitations and nervousness. Numerous studies by other authors have shown that FD stems from psychosocial disturbances; functional diseases were often observed in people with mood, nervous or emotional disorders $[3,23,38]$. On the other hand, as in other functional disorders, there always remains the question of whether these symptoms are the cause of dyspepsia or its effect, resulting from the patient's anxiety about their own health.

In the functional dyspepsia group a statistically significant correlation between sex, age, season and $H$. pylori infection was also demonstrated $(p<0.05)$.

In dealing with patients with symptoms of dyspepsia the intensity and duration of symptoms and their impact on the quality of life should be taken into account. The treatment procedure is meant to provide relief [3, 39-42]. Numerous studies have shown more frequent $H$. pylori infection in patients with functional dyspepsia than in the control population. However, despite the differences in infection in the analysed socioeconomic and ethnic groups, there was no difference in the frequency of occurrence of functional dyspepsia. Eventually, both on the basis of the literature and the author's own research, the role of $H$. pylori infection in FD has not been determined [43, 44].

Functional dyspepsia division into subgroups can give information about the pathogenesis of symptoms, although the value of such an assessment is insufficient. In fact, there are no studies that distinguish the specificity of symptoms in the groups of functional disorders. It seems, therefore, that the division is too artificial. Classification based on the symptoms of dyspepsia has $94 \%$ specificity, but a sensitivity of $57 \%$. Therefore, this division was not analysed in this study.

It was found that $40 \%$ of patients with dyspeptic symptoms seek medical help. It seems that the problem is much larger than shown here, because our study was based on patients who reported to the doctor. At the turn of the century functional diseases began to play a more important role, and therefore the problem of quality of life of these patients is growing; it refers not only to the problem of pain, but also to the side effects of treatment $[39,40]$. Functional gastrointestinal disease is also a common (20-30\%) problem of functional disorders of the lower gastrointestinal tract, in the form of IBS. In patients with functional dyspepsia, who more frequently were women, the symptoms did not affect the assessment of their health and wellbeing to a great extent. In our study, those patients evaluated their well-being as good; compared to the irritable bowel syndrome group the rank of socioeconomic phenomena seemed to be lower, our patients rarely reported the necessity to take sick leave due to the reported ailments, but in a subjective assessment their health was worse than the health of other people from their immediate environment [41, 42, 45, 46].

Psychogenic factors are more frequently acknowledged as being a contributing factor to dysregulation of the brain-gut axis. Disturbances of different levels of control might influence excretory and immunological function as well as severity of coeliac symptoms arising from the digestive tract $[47,48]$.

In conclusion, the frequency of functional dyspepsia in the study group is similar to that described in western societies ( $23 \%$ vs. $25 \%$ ). Functional dyspepsia is more common in young women and does not show typical seasonality of symptoms, the psychological profile of the patients is similar to the psychological profile of patients with IBS and the patients often report accompanying symptoms not related to the gastrointestinal tract, although self-esteem in this group, despite the chronic nature of the condition, is good. The incidence of $H$. pylori infection does not exceed that observed in the clinical population. Neither the presence of $H$. pylori infection nor the eradication therapy appear to be relevant in terms of symptoms, while the efficacy of PPI treatment is observed only at the time of administration of the drugs. All (100\%) patients with functional dyspepsia infected with $H$. pylori had inflammatory lesions of varying severity in the stomach; in uninfected patients the changes were smaller, but there were no microscopic inflammatory changes only in 9.4\% (5 subjects) in the study sample. This undermines the validity of the diagnosis of the functional nature of the symptoms in these patients.

\section{Conclusions}

The problem of functional dyspepsia refers to quite a large number of patients; statistics in western countries show that approx. 23-25\% of society suffers seasonally from such ailments. Despite diverse functional dyspepsia pathogenesis concepts, referring to motor disorders, secretion, visceral pain threshold and impact of $H$. pylori infection, no homogenous pathophysiological grounds for this illness have been determined yet.

The aim of this thesis is an attempt to assess the problem of functional dyspepsia in a study sample selected from the Polish population. The group, qualified for the research in accordance with the thesis assump- 
tions, consisted of 230 people matching Rome Criteria II for dyspepsia. In terms of sex, the largest group consisted of women -140 subjects (60.9\%), aged $46-60$ years $(33.5 \%)$. Patients sought medical help because of dyspeptic disorders mostly in autumn and winter (61.7\%). Helicobacter pylori infection assessed using the urease test was detected in 181 subjects out of 224 examined (81.2\%). Depending on the endoscopic image, the clinical population was divided into illness groups; functional dyspepsia included 53 people (23\%); dyspeptic symptoms were more frequent among women (42 subjects $-79.2 \%$ ) and occurred mostly with the $1^{\text {st }}$ and $2^{\text {nd }}$ age groups (16-45 years) $(75.5 \%)$.

Those patients visited the clinic due to dyspeptic ailments most often in autumn - 24 subjects (45.3\%). The influence of eradication therapy on mood was assessed. Nineteen out of 23 subjects reported better mood, and 4 subjects described it as bad despite successful eradication of $H$. pylori. After 6 months questionnaires were sent to the clinical population. The subjects were asked to assess their mood. Twenty-three answers were received (43.4\%), out of which 20 (86.9\%) reported worsened mood, and only 3 subjects stated (13.1\%) that they felt better. It was revealed that with patients suffering from $\mathrm{H}$. pylori infection, the inflammatory lesions of the gastric mucus membrane occurred in $100 \%$ of cases and were at least moderately intense; for persons without the infection these changes were much less intense, although no microscopic changes were observed only in 5 (9.4\%) subjects out of 16 .

The results of comparison of mood among the groups (infected not eradicated, infected eradicated, and not infected) were not statistically significant either, both directly after treatment and after 6 months.

Another element was an attempt to analyse socioeconomic factors and to characterize the group of patients with functional dyspepsia.

In order to do this, the Gast 2001 questionnaire was analysed. Its detailed results were presented in the thesis. Summing up the most frequent answers, it is worth emphasizing the frequent coexistence of general non-gastric symptoms with these patients, such as headaches, weakness, nervousness and little resistance to stress, as well as their occurrence mostly in persons with higher education, who had not been ill before and had not had any prior surgical operations. Despite the chronic nature of their ailments, these patients assessed their mood as quite good and rarely took sick leave.

The conducted research allowed the following conclusions to be drawn: the frequency of functional dyspepsia in the study sample is similar to the frequency described in western societies (23\% vs. $25 \%$ ). Func- tional dyspepsia occurs more frequently among young women, it is not seasonal and patients' psychological profiles are similar to the psychological profiles of patients with IBS. Patients often report accompanying non-gastric symptoms. Despite the chronic nature of the symptoms, self-esteem in this group is good. The frequency of $H$. pylori infection does not exceed that observed in the clinical population. The presence of H. pylori infection, as well as eradication therapy, does not seem to matter from the perspective of illness symptoms. On the other hand, the efficiency of the PPI treatment is observed only at the time of drug administration. In the case of subjects with functional dyspepsia, who are infected with $H$. pylori, various intensified inflammatory lesions in stomach were observed in 100\% of cases. Among subjects without inflammation, lesions were smaller; nevertheless, no microscopic inflammatory lesions were observed only among $9.4 \%$ of cases (5 subjects) from the study sample, which may undermine the legitimacy of diagnosed functional disorders with these patients.

Due to the very high ratio of subjects with functional dyspepsia, also observed in the study sample, and the influence of civilization progress, we should expect increasing frequency of occurrence of this problem.

\section{References}

1. Konturek SJ. Clinical gastroenterology and hepatology [Polish]. PZWL, Warsaw 2001; 129-52, 160-2, 172-6, 225-31.

2. Traczyk W, Trzebski A. Human physiology with elements of clinical physiology [Polish]. PZWL, Warsaw 1980; 689-751.

3. Holtmann G, Talley NJ. Functional dyspepsia. Current treatment recommendations. Drugs 1933; 45: 918-30.

4. Piotrowicz G. Functional dyspepsia - reasons, clinical image and rules of treatment of patient [Polish]. Probl Lek 2001; 40: 364-8.

5. Waluga M, Jonderko K, Kasicka-Jonderko A, Kamińska M. Influence of eradication of inflammation on defecation at patients with dyspepsia. Prz Gastroenterol 2011; 6: 118-24.

6. Wiśniewska-Jarosińska M, Harasiuk A, Klupińska G, Chojnacki C. Utility in indication of density of serotonin in blood and 5-HTI acid in urine in diagnostics of functional dyspepsia. Prz Gastroenterol 2010; 5: 285-91.

7. Talley NJ, Weaver AL, Zinsmeister AR, Melton LJ 3rd. Onset and disappearance of gastrointestinal symptoms and functional gastrointestinal disorders. Am J Epidemiol 1992; 136: 165-77.

8. Ryżko J. III Roma classification disturbances of digestive system youth and child period. Prz Gastroenterol 2008: 3: 79-86.

9. Talley NJ, Stanghellini V, Malagelada JR, Tytgat GNJ. Functional diseases of stomach and duodenum. Med Prakt 2002; 8 Suppl. 13-23

10. Mearin F, Cucala M, Azpiroz F, Malagelada JR. The origin of symptoms on the brain - gut axis in functional dyspepsia. Gastroenterology 1991; 101: 999-1006. 
11. Talley NJ, Fung LH, Gilligan IJ, et al. Association of anxiety, neuroticism, and depression with dyspepsia of unknown cause. A cause- control study. Gastroenterology 1989; 90: 886-92.

12. Verdu EF, Fraser R, Tiberio D, et al. Prevalence of infection and chronic dyspeptic symptoms among immigrants from developing countries and people born in industrialized countries. Digestion 1996; 57: 180-5.

13. Boyd EJ. The prevalence of esophagitis in patients with duodenal ulcer or ulcer-like dyspepsia. Am J Gastroenterol 1996; 91: 1539-43.

14. Talley NJ, Zinsmeister AR, Schleck CD, Melton LJ 3rd. Dyspepsia and dyspepsia subgroups: a population-based study. Gastroenterology 1992; 102: 1259-68.

15. NIH Consensus Conference. Helicobacter pylori in peptic ulcer disease. NIH Consensus Development Panel on Helicobacter pylori in Peptic Ulcer Disease. JAMA 1994; 272: 65-9.

16. Armstrong D. Infection and dyspepsia. Scand J Gastroenterol 1996; 31: Suppl.: 215

17. Bernersen B, Johnsen R, Bostad L, et al. Is Helicobacter pylori the cause of dyspepsia? Br Med J 1992; 304: 1276-9.

18. Hammer B, Staub P, Meyer M. Triage, probatiory therapy with cisapride and follow-up of functional reflux and dyspepsia. Gut 1994; 35: A 76 ( 1158 ).

19. Talley NJ, Weaver AL, Tesmer DL, Zinsmeister AR. Lack of discriminant value of dyspepsia subgroups in patients referred for upper endoscopy. Gastroenterology 1993; 105: 1378-86.

20. Talley NJ. A critique of therapeutic trials in positive functional dyspepsia. Gastroenterology 1994; 106: 1174-83.

21. O'Morain C, Gilvarry J. Helicobacter pylori and dyspepsia. Scand J Gastroenterol Suppl 1996; 214: 28-3.

22. Bytzer P, Hansen JM, Schaffalitzky de Muckadell OB. Empirical $\mathrm{H} 2$-blocker therapy or prompt endoscopy in management of dyspepsia. Lancet 1994; 343: 811-6.

23. O'Morain C, Gilvarry J. Eradication of in patients with non-ulcer dyspepsia. Scand J Gastroenterol Suppl 1993; 196: 30-3.

24. Przytulski K. Functional dyspepsia [Polish]. Warszawa 2001

25. Johnsen R, Bernersen B, Straume B, et al. Prevalences of endoscopic and histological findings in subjects with and without dyspepsia. Br Med J 1991; 302: 749-52.

26. Talley NJ. Helicobacter pylori and non-ulcer dyspepsia. Scand J Gastroenterol Suppl 1996; 220: 19-22

27. Malagelda JR. Gastrointestinal motor disturbances in functional dyspepsia. Scand J Gastroenterol Suppl 1991; 182: 29-32.

28. Jones R, Lydeard S. Dyspepsia in the community: a follow-up study. Br J Clin Pract 1992; 46: 95-7.

29. Zant W. Helicobacter pylori et non-ulcer dyspepsia. Scand J Gastroenterol 1991; 3: 463-8.

30. Elta GH, Scheiman JM, Barnett JL, et al. Long-term follow-up of Helicobacter pylori treatment in non-ulcer dyspepsia patients. Am J Gastroenterol 1995; 90: 1089-3.

31. Drossman DA, McKee DC, Sandler RS, et al. Psychosocial factors in the irritable bowel syndrome. Gastroenterology 1988; 95: 701-8.

32. Tucci A, Corinaldesi R, Stanghellini V, et al. Infection and gastric function in patients with chronic idiopathic dyspepsia. Gastroenterology 1992; 89: 1797-800.

33. Soll AH. Practice Parameters Committee of the American College of Gastroenterology, Consensus conference. Medical treatment of peptic ulcer disease. Practice guidelines. JAMA 1996; 275: 622-9

34. Jönsson KA, Gotthard R, Bodemar G, Brodin U. The clinical relevence of endoscopic and histologic inflammation of gastroduodenal mucosa in dyspepsia of unknown origin. Scand J Gastroenterol 1989; 24: 385-95.

35. Bytzer P, Moller-Hansen J, Schaffalitzky de Muckadell O. Symptom grouping in dyspepsia. Any predictive value ? Scand J Gastroenterol 1993; 28 Suppl.: 197.

36. Tack J, Bisschops R, Sarnelli G. Pathophysiology and treatment of functional dyspepsia. Gastroenterology 2004; 127: 1239-55.

37. Greenberg P, Cello J. Lack of treatment for Helicobacter pylori on symptoms of nonulcer dyspepsia. Arch Intern Med 1999; 159: 2283-8.

38. Farup PG, Hovde O, Breder O. Are frequent short-oesophageal reflux episodes the causes of symptoms in patients with non-ulcer dyspepsia responding to treatment with ranitidine? Scand J Gastroenterol 1995; 30: 519-23.

39. Kalantar J, Xia H. Determination of optimal biopsy sites for detection of $\mathrm{Hp}$ in patients treated or not treated with antibiotic and antisecretory drugs. Gastroenterology 1997; 112 A: 165-9.

40. Rydzewska G. Jakość życia w zespole jelita nadwrażliwego - czy mamy świadomość cierpienia pacjenta [Polish]? Gastroenterologia w Codziennej Praktyce Lekarskiej 2003; 8: 4-11.

41. Arnold R, Fischer M, Koelz HR. Treatment of Hp infection at people with functional dyspepsia based on standard treatment - research FROSCH. [Polish]. Med Prakt 2003; 147: 170-7.

42. Yoon JH, Baik GH, Sohn KM, et al. Trends in the eradication rates of infection for elevens years. World J Gastroenterology 2012; 18: 6628-34.

43. Iwańczak F, Iwańczak B. New perspective of the treatment ofHelicobacter pylori infection. Prz Gastroenterol 2011; 6: 364-9.

44. Thor P. Electrogastrophy in diagnostics et treatment of functional disturbances of stomach [Polish]. Gastroenterol Pol 1995; 2: 371-9.

45. Urbain JL, Vekemans MC, Parkman H, et al. Dynamic antral scintigraphy to characterize gastric antral motility in functional dyspepsia. J Nucl Med 1995; 36: 1579-86.

46. Kim HI, Jung SA, Choi JY, et al. Impact of shiftwork on irritable syndrome and functional dyspepsia. J Korean Med Sci 2013; 28: 431-7.

47. Quigley EM. Bugs on the brain; brain in the gut-seeking explanations for common gastrointestinal symptoms. Ir J Med Sci 2013; 182: 1-6.

48. Dragoş D, lonescu O, Micuț R, et al. Psychoemotional features of a doubtful disorder: functional dyspepsia. J Med Life 2012; 5: $260-76$.

Received: 1.04.2013

Accepted: 5.06 .2013 